This is an electronic reprint of the original article. This reprint may differ from the original in pagination and typographic detail.

Author(s): Silvennoinen, Minna; Pirhonen, Antti

Title: $\quad$ Educational Application Design Process Experiences : Case Perioperative Nursing

Year: $\quad 2014$

Version:

Please cite the original version:

Silvennoinen, M., \& Pirhonen, A. (2014). Educational Application Design Process Experiences : Case Perioperative Nursing. In S. Zvacek, M. T. Restivo, J. Uhomoibhi, \& M. Helfert (Eds.), CSEDU 2014 : Proceedings of the 6th International Conference on Computer Supported Education : Vol. 1 (pp. 545-550). SCITEPRESS - Science and Technology Publications. https://doi.org/10.5220/0004960505450550

All material supplied via JYX is protected by copyright and other intellectual property rights, and duplication or sale of all or part of any of the repository collections is not permitted, except that material may be duplicated by you for your research use or educational purposes in electronic or print form. You must obtain permission for any other use. Electronic or print copies may not be offered, whether for sale or otherwise to anyone who is not an authorised user. 


\title{
Educational Application Design Process Experiences Case Perioperative Nursing
}

\author{
Minna Silvennoinen, Antti Pirhonen \\ Department of Computer Science and Information Systems \\ University of Jyväskylä, Finland \\ \{first name, last name\}@jyu.fi
}

Keywords: Perioperative nursing, game development, nursing competencies, learning objectives, educational application success

Abstract: From an educational point of view, the only relevant basis for the design of an educational application is the learning objectives of the content area. In the development process of an educational application, there are also other people involved besides educational experts. This paper describes a project which primarily aims at developing an application for the needs of enhancing perioperative nursing skills'.

Besides application development, the project included research about the process. The research task was to discover how the real - not only the formal - objectives could work as the starting point for the construction of an educational game-like application. This paper presents the study process based on the panel discussions of nursing teachers. In the panels, the teachers elaborated the objectives. The transcribed discussions were analysed in terms of conceptions of learning and teaching of perioperative nursing.

The outcomes, the elaborated objectives, were aimed to be used as a basis for the implementation of an educational game. In addition, the discussions were analysed from the perspective of the learning paradigm they reflected. It is argued that views of learning are necessary to be understood in order to make appropriate choices of educational strategy throughout the development process. Finally, this paper presents initial observations of a user study of the game. They are discussed from the point of view of project success and the potential of the chosen approach. It is concluded that the construction of this kind of game is a much more effective means of learning than the playing of it, thus suggesting that students themselves should be used as authors.

\section{INTRODUCTION}

The purpose of constructing an educational application is - or at least should be - to promote learning. Therefore, learning objectives should be the primary criteria in all stages of the development. However, it is far from clear regarding what the objectives are when educating perioperative nurses. We know that perioperative nurses' work in operating department and their role at the hospital is to provide care to the patients independently and responsibly together with other healthcare professionals. These nurses provide care and support to patients before, during, and after surgery (pre- intra- and post-operatively). Perioperative nurses' responsibilities prior and during surgery are, for example, instrument and sterile environment preparation and maintenance, and assisting surgeons during the operation (Mitchell \& Flin, 2008).
Perioperative nursing skills include cognitive, social and technical components such as using various operating theatre (OT) equipment. Sometimes highly automatised technical skills are needed; sometimes fast reasoning and reaction should be applied to constantly changing treatment situations and a wide variety of different patients. Therefore decisionmaking skills, adaptability to new situations, as well as competence in evaluating rapidly changing and challenging situations are important. Also ethical considerations and problem solving is needed. Perioperative nurses are required to work in teams with other healthcare professionals, including multiprofessional teams, thus group work skills are essential. Perioperative work environment is also stressful and often physically straining, which should be taken into account in their education.

Patient safety and patient care are core elements of perioperative nursing. Nurse education is a central 
means to reduce or prevent noticeable risks and errors in perioperative work (McConnell \& Hillbig, 2000; Pirhonen \& Silvennoinen, 2011). All these requirements should be acknowledged when designing and implementing new ways to train perioperative nurses. Suitable means for responding to these requirements should be explored.

There are studies presenting the perioperative nurse's skills and requirements in the forms of required competences which should be developed through clinical learning activities such as knowledge, skills and values. These are presented in Table I (AORN, 2007).

Table I. Perioperative Nurse's Competencies

\begin{tabular}{|c|c|}
\hline \multirow{3}{*}{ 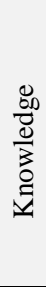 } & $\begin{array}{l}\text { Applying knowledge on anatomy, physiology, } \\
\text { and pathophysiology to understand the procedure, } \\
\text { its effects on the patient and patient needs }\end{array}$ \\
\hline & $\begin{array}{l}\text { Recognising ethical and legal responsibilities, the } \\
\text { nurse's accountability to the patient, the } \\
\text { profession of nursing and team work }\end{array}$ \\
\hline & $\begin{array}{l}\text { Applying research findings to planning and } \\
\text { implementing effective perioperative care }\end{array}$ \\
\hline \multirow{3}{*}{$\stackrel{n}{=}$} & Learning and refining aseptic techniques \\
\hline & $\begin{array}{l}\text { Improving patient assessment, communication, } \\
\text { organisation, coordination, critical-thinking, and } \\
\text { decision-making skills in an environment where } \\
\text { such activities must be performed quickly and } \\
\text { accurately }\end{array}$ \\
\hline & $\begin{array}{l}\text { Providing opportunities to assess own interest and } \\
\text { talents }\end{array}$ \\
\hline \multirow[b]{4}{*}{ 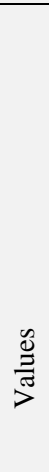 } & $\begin{array}{l}\text { Developing the role of advocate for the patient by } \\
\text { identifying the patient's expressed and } \\
\text { unexpressed needs }\end{array}$ \\
\hline & $\begin{array}{l}\text { Responding to those needs through the action of } \\
\text { facilitating or mediating among all providers } \\
\text { involved in the care process }\end{array}$ \\
\hline & $\begin{array}{l}\text { Recognising diverse career opportunities in } \\
\text { perioperative settings }\end{array}$ \\
\hline & $\begin{array}{l}\text { Participating as a member of multi-professional } \\
\text { health care team that develops and promotes the } \\
\text { continuity of patient care in an environment that } \\
\text { reinforces an understanding of a nurse's } \\
\text { independent and interdependent function }\end{array}$ \\
\hline
\end{tabular}

Perioperative nurses' core competencies are critical-thinking and sound clinical judgment which should be used effectively to meet patient needs (Cafira, \& Janiszewski Goodin, 2011). Criticalthinking and clinical decision-making skills are essential components which are acquired in perioperative work. These can be learned for example with concept mapping which is a tool for efficiently perceiving relationships between concepts (Noonan, 2011). Critical-thinking and decision-making skills could also be learned with the help of educational games which foster collaboration and critical-thinking among peers and associates (Cafira, \& Janiszewski Goodin, 2011).

Due to the extremely diversified contents of perioperative nursing skills, it is relevant to consider the application of computers in this education. This paper discovers the potential of interactive technology in the education of perioperative nursing. The paper draws on an application development project, in which the authors participated particularly as experts of education.

In the current case study, the application of interactive technology was inspired by previous, successful application of computers in the teaching of nursing skills (Huff, 2003; Cafira, \& Janiszewski Goodin, 2011). In these studies, computer-based educational games, such as web-based courses including quizzes, examinations and reviews were applied and some learning benefits discovered. In the teaching of perioperative nursing, using games to teach, learn, and reinforce perioperative material through experiential techniques has potential in promoting critical-thinking (Sewchuk, 2005; Cafira, \& Janiszewski Goodin, 2011).

\subsection{Related project}

The current study is based on an assignment, in which a prototype of an educational game for the educational needs of perioperative nursing was supposed to be implemented. The development project group consisted of specialists from three large organisations. The teachers of nursing education (University of Applied Sciences), education and usability researchers (University) and nurses working in the field (hospital), as well as other IT and management professionals. In addition, there was a project leader and responsible leaders of each participating organisation. The main realiser of the game construction was an independent IT software company which was selected based on an open bidding competition.

\section{THE ORGANISATION OF THE STUDY}

The organisation of teaching is a complicated process in which learning is the primary objective. Typically, the role of an individual teacher is central - his or her conception about what learning is and how it could be promoted. Also, the teacher's view 
of the curriculum is obviously pivotal in terms of what content is important and what is not. The conclusion is obvious: more important than what is told in the formal curricula is the teacher's interpretation or conception of the curricula.

In the current study, we combined the handling of curricula and learning conceptions in one single empirical setting. We first prepared a tentative set of learning objectives for perioperative nursing. By learning objectives we mean both the formal objectives which are written in curricula, as well as the objectives that the teacher is implementing, which arise from numerous sources, such as formal documents. In the current study, we seek the socalled 'hidden curriculum' as well. The tentative set of objectives was based on the formal objectives of the local school which educates nurses (JAMK University of Applied Sciences, see http://www.jamk.fi/). These tentative objectives were then elaborated by two expert panels, each of which consisted of three experienced nursing teachers from JAMK. The panels were moderated by a researcher, who recorded the discussions. In the panel sessions, the objectives were discussed in the order of objective categories. Each panel session took about 60 minutes. After the panel sessions, the objective table was finalised by the researcher.

The recordings of the discussions were transcribed. The transcriptions were analysed in terms of conceptions of learning. The expressions that the teachers used were classified according to the perspective of learning that they reflected; behaviourist, cognitivist, or constructivist. This set was then presented to two independent teacher panels, in order to discuss and elaborate the proposed objectives.

\section{CASE STUDY: OBJECTIVES IN STUDYING PERIOPERATIVE NURSING}

The tentative table of objectives was elaborated by two expert panels. The structure of the table follows the widely used categorisation: Knowledge, skills and attitudes, each of which is handled concerning theoretical, professional, social and ethical aspects. We now present the elaborated version of the objectives in four separate tables: theoretical (Table II), professional (Table III), social (Table IV), and ethical (Table V). The objectives in the tables should be read by starting each objective with "After studying perioperative nursing, the student..." The numbers in the parentheses at the end of each category in Tables 2-5 indicate the number of comments in the transcription.

Table II. Theoretical Aspects

\begin{tabular}{|l|l|}
\hline & $\begin{array}{l}\text { Has acquired the core concepts of perioperative } \\
\text { nursing to the level required for the construction of } \\
\text { theoretical knowledge in the area. (13) }\end{array}$ \\
\hline & $\begin{array}{l}\text { Utilises relevant literature in the area of expertise } \\
\text { in order to construct knowledge. Is capable of } \\
\text { critically assess references and is able to apply the } \\
\text { constructed knowledge in an appropriate manner. } \\
\text { (10) }\end{array}$ \\
\hline \multirow{2}{*}{$\begin{array}{l}\text { Is interested in nursing practices and science } \\
\text { related issues in diverse contexts. Understands the } \\
\text { significance of continual construction of new } \\
\text { knowledge in the development of him/herself and } \\
\text { his/her expertise, as well as in the securing and } \\
\text { promoting of the function of his/her group and the } \\
\text { whole organisation. (1) }\end{array}$} \\
\hline
\end{tabular}

Table III. Professional Aspects

\begin{tabular}{|c|c|}
\hline $\begin{array}{l}\frac{8}{80} \\
\frac{0}{3} \\
0 \\
1 \\
1\end{array}$ & $\begin{array}{l}\text { Is aware of his/her professional strengths and } \\
\text { recognises areas which require further } \\
\text { development. (31) }\end{array}$ \\
\hline$\frac{\mathscr{J}}{\tilde{v}}$ & $\begin{array}{l}\text { Is able to work by applying the approaches, } \\
\text { methods and principles of perioperative nursing, in } \\
\text { terms of his/her own role, in a patient-centric } \\
\text { manner, taking care of patient safety. Applies } \\
\text { his/her professional skills and knowledge, such as } \\
\text { clinical skills, medication, infection prevention, } \\
\text { pain treatment and decision-making skills in an } \\
\text { appropriate way. Detects problems and uses } \\
\text { creative problem-solving in decision-making. High } \\
\text { pressure tolerance. Monitors, assesses and reflects } \\
\text { his/her own work critically. Promotes mental and } \\
\text { physical well-being in work and occupational } \\
\text { health and safety through his/her own activity. (27) }\end{array}$ \\
\hline 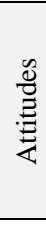 & $\begin{array}{l}\text { Is willing to learn new things in the domain of } \\
\text { nursing. Understands the importance of his/her } \\
\text { expertise from the point-of-view of the work } \\
\text { community and society as a whole, and is proud of } \\
\text { it. Understands his/her own personal responsibility } \\
\text { as an expert of nursing. (24) }\end{array}$ \\
\hline
\end{tabular}


Table IV. Social Aspects

\begin{tabular}{|c|c|}
\hline 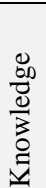 & $\begin{array}{l}\text { Conceptualises nursing as human-centred and, in } \\
\text { particular, patient-centred work, in which social } \\
\text { interaction plays a central role. Understands the } \\
\text { aspects of group forming and functioning. (6) }\end{array}$ \\
\hline$\frac{n}{\frac{\pi}{5}}$ & $\begin{array}{l}\text { Is able to work all-round and interact as a member } \\
\text { of diverse groups. Is able to work in different kinds } \\
\text { of patient related situations in an interactive } \\
\text { manner, taking the individuality of a patient into } \\
\text { account. Is capable of contributing constructively } \\
\text { to the forming of a group, as well as to the } \\
\text { achieving the of objectives of the group. Is able to } \\
\text { act according to his/her own role in the group work } \\
\text { context. Is able to utilise and provide feedback. } \\
\text { Recognises phenomena relating to group dynamics, } \\
\text { and reacts to them appropriately (context } \\
\text { sensitivity). (20) }\end{array}$ \\
\hline 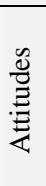 & $\begin{array}{l}\text { Understands his/her personal role as a member of a } \\
\text { group and the significance of working together in } \\
\text { order to achieve the common objectives. } \\
\text { Understands his/her role from the patient's } \\
\text { perspective. Accepts differing viewpoints. (7) }\end{array}$ \\
\hline
\end{tabular}

Table V. Ethical Aspects

\begin{tabular}{|c|c|}
\hline $\begin{array}{l}\frac{0}{0} \\
\frac{0}{0} \\
\frac{0}{2} \\
0 \\
\frac{1}{2}\end{array}$ & $\begin{array}{l}\text { Is aware of the ethical issues and perspectives of } \\
\text { nursing. Knows the commonly agreed and } \\
\text { contradictory values related to nursing. } \\
\text { Understands the challenges and opportunities of } \\
\text { multicultural settings from the point-of-view of } \\
\text { own work community. (6) }\end{array}$ \\
\hline$\frac{a}{\bar{n}}$ & $\begin{array}{l}\text { Recognises and is able to analyse ethical issues of } \\
\text { nursing, and is able to solve and apply them } \\
\text { appropriately. Follows the widely accepted ethical } \\
\text { principles of nursing. Is able to assess his/her own } \\
\text { work against ethical criteria. Dares to tackle } \\
\text { detected flaws and solve them constructively. (3) }\end{array}$ \\
\hline 窇 & $\begin{array}{l}\text { Considers ethical issues pivotal for nursing. Is } \\
\text { willing to promote community discussion about } \\
\text { ethical issues through his/her part in his/her work. } \\
\text { Interprets the treatment of patients, colleagues and } \\
\text { other members of the work community primarily as } \\
\text { an ethical issue. (1) }\end{array}$ \\
\hline
\end{tabular}

As can be seen, professional knowledge, skills and attitudes clearly evoked the most discussion. It appears that attitudes other than purely professional ones did not get much attention. On the basis of our data it is difficult to say whether this indicates lower prioritisation or whether it is simply an area that is more difficult to verbalise, and in turn difficult to discuss. Ethical issues induced surprisingly little discussion - again, the reason is difficult to see on the basis of the current data.

\section{FORMULATING INTERACTIVE APPLICATION OBJECTIVES FOR LEARNING PERIOPERATIVE NURSING}

The central education research aim in this project was to produce knowledge and test how the real not only the formal - objectives could work as the starting point for the construction of an educational game. Applying these discovered objectives into the game development was the subsequent goal after this study. The game development had already begun before the research results were finished. However, the purpose to form a basis for an educational application based on these learning objectives still seemed possible, because no actual content of the game had been build. Some central decisions, such as programming language and platform of the game had already been decided within the leading organisation, based on the recommendations of the software company. The university researchers in this game development project operated as consultants making suggestions and recommendations based on the study. These recommendations for the game execution were presented in the project group meetings. For example, the learning objective tables were suggested to be used while combining the content of the game such as tasks for the students to solve during playing. Also, content examples were offered to the content providers (specialists in nursing science). The most important recommendation was that the objectives of perioperative nursing education should be the basis of the whole application. Or if the application would only cover a portion of the educational objectives, the minimum requirement would be that the application is not in contradiction with the objectives. In other words, it is overly ambitious to aim at covering the whole content of education with one single application. Yet, still it should follow the principles that the over-all objectives indicate.

When we first prepared a tentative set of objectives on the basis of the formal curriculum and then elaborated it with the teachers, we found that teachers' conceptions were well in line with the formal objectives. In other words, this study did not reveal a dominant hidden curriculum, but the formal curriculum has been developed in parallel with 
practical needs, thus making a lot of sense for the teachers. While the discussions concerned the existing learning objectives, it can be concluded that the teachers think that perioperative nurses need several sorts of skills, ranging from highly automatised routines to the ability to act creatively when necessary.

When we reflected on the objectives in light of the strengths of educational games, it became evident that only certain kinds of objectives can be covered with a game, no matter how sophisticated it may be technically or pedagogically. The widely acknowledged strength of an educational game is that it is a motivating means to train skills which require a large amount of repetition. As discussed above, perioperative nursing includes these kinds of skills which are typically highly automatised routines. At least in the training of these routines, games have potential. From the point-of-view of the application to be designed, this would mean that all the objectives of perioperative nursing education are not appropriate for inclusion into the pedagogical requirements of the forthcoming application.

\section{APPLYING THE LEARNING OBJECTIVES}

During the game development, the nursing teachers and student groups were acting as the main content providers. This task however proved very challenging, in spite of the previously defined learning aims. The content providing was heavily restricted by the technological limitations of the software. As a result, only certain types of computer assisted learning could be implemented, such as multiple choice questions. In order to cover all the aspects of the perioperative nursing skills addressed earlier, this is obviously not adequate. Formulating the questions which address, for example, ethical attitudes and the learner's inner state of mind could be rather complicated to put into practice this way. Even though the game technology also afforded open questions, the analysis of the success or failure of the learner's answers became impossible. Therefore, the questions applied in the game prototype covered almost solely professional skills and theoretical knowledge. This gave the game a certain form of written examination with multiple choice questions, even though videos and pictures were added to provide variation.

There are several risks for the success of learning with this kind of game. It is overly ambitious to assume that the players would maintain a high level of motivation after playing a few times. The questions measuring only superficial learning or memory are hardly challenging. The problemsolving tasks which require applying own reasoning and reflection and which do not necessarily have only one right or wrong answer would be much more practical within this learning context. Gametype learning always requires some kind of measurement of success or failure. It should also include some form of competition in order to be motivating and addictive for the player. It can be stated that the objectives of perioperative nursing skills learning are hardly always issues which can be used in a competitive form or measure at all. Sometimes this issue and the issue of game playing could even be in contradiction to one another.

The success of the project can be measured by varying criteria. A suitable one in this developmental project context is the result and product success. The different stakeholders, e.g. contractors, sponsors, project managers, team members, users, ICT developers etc. might see the project goals as well as the product success in a number of ways (Pirhonen, 2013). According to Pirhonen (2013), product success is a longitudinal measurement which can be assessed according to several criteria: whether it meets the organisational strategic objectives, how satisfying it is for users and stakeholder needs, what the business success is and what the financial rewards are. These can be completely verified once the product, in this case an educational game, has been utilised. The result from the various viewpoints can be that the objectives of the game development project are not solely the same as the objectives of the education research aiming at maximal skills and learning objective attainment. Sometimes the game development project is guided by a strict budget and objectives to develop visibly measurable results for the financing organisation as fast and efficiently as possible. The consequences of the differing aims and viewpoints should however be acknowledged and understood while evaluating both the product and the entire success of the project. In this project, the development of a prototype of an educational game was in many ways successful and the quantitative requirements were fulfilled. Yet, the acknowledged shortcomings relating to learning content were clearly an issue to address when the follow-up project was launched at the beginning of 2014 .

One definite conclusion is that at the beginning of the project, the technical implementation of the application was seen as the major challenge. Having 
recently conducted a concise user study with six students, we argue, however, that the real challenge is in the authoring of the content, not the technical issues. The application itself mainly supports low level learning. The construction of the content, on the contrary, may be much more demanding. If the students of nursing are contributing to the content of the game, this authoring process may be a much more rewarding learning process than the actual playing of the game. In other words, the authoring of the relatively primitive game works as a framework or excuse for an activity, during which higher order thinking skills are applied.

In the near future we will analyse the work of student groups: How they generate game ideas and how the application supports the implementation of the ideas.

\section{ACKNOWLEDGEMENTS}

The work is funded by European Social Fund (ESF) in Finland.

\section{REFERENCES}

Sewchuk, D., 2005. Experiential learning-A theoretical framework for perioperative education. AORN Journal 81(6), 1311-1317.
AORN, 2007. Guidance Statement: The value of clinical learning activities in the perioperative setting in undergraduate nursing curricula. AORN Journal 86(2), 265-269.

Cafira, L., Janiszewski Goodin, H., 2011. Using games to provide interactive perioperative education. AORN Journal 94(4), 370-248.

Huff, M., 2003. Web-enhanced learning for perioperative nurses. SSM, 9(3), 53-55.

McConnell, E. Hillbig, A., 2000. A National Study of Perioperative Nurse Education in Two Technologies. AORN Journal 72(2), 254-264.

Mitchell, L., Flin, R., 2008. Non-technical skills of the operating theatre scrub nurse: literature review. Journal of Advanced Nursing 63(1), 15-24.

Noonan, P., 2011. Using concept maps in perioperative education", AORN Journal 94(5), 469-478.

Pirhonen, A., Silvennoinen, M., 2011. Aims vs. Technology: Pedagogical view to the use of educational applications in safety critical contexts. In proceedings of IEEE 1st International Conference on Serious Games and Applications for Health (SEGAH 2011), November 16-18 2011, Braga, Portugal, 88-94.

Pirhonen, M., 2013. Supporting the success of an information systems project: viewpoints an education and replacement of the project manager. Jyväskylä studies in computing 172.

http://urn.fi/URN:ISBN:978-951-39-5475-8 